\title{
Neurobiology and Management of Attention-Deficit/Hyperactivity Disorder and Co-Occurring Major Depressive Disorder: Complications and Strategies
}

Birabwa Kayongo*

School of Pharmacy, Hage Geingob Campus, University of Namibia, Namibia

Article History
Received: 18.09 .2020
Accepted: 09.10 .2020
Published: 28.12 .2020
Journal homepage:
https://www.easpublisher.com

Abstract: Attention-deficit/hyperactivity disorder (ADHD) is a contentious diagnostic issue, which has been increasing in prevalence in recent years, and is often comorbid with major depressive disorder (MDD). The common features of ADHD and MDD are altered activation of brain regions involved in rewarding processing and monoamine signalling. ADHD responds well to a multimodal treatment that consists of pharmacological and psychosocial interventions. Its treatment responsiveness improves mood and well-being. There is persistent debate around the use of catecholaminergic agents such as psychostimulants both in ADHD and in the treatment of depression. This review will focus on the neurobiology of both psychopathologies and how they intertwine, and consider the potential benefits and adverse effects of catecholaminergic agents in the treatment of ADHD and co-occurring MDD.

Keywords: ADHD, MDD, comorbid, reward, monoamines, pharmacological, psychosocial.

Copyright (C) 2020 The Author(s): This is an open-access article distributed under the terms of the Creative Commons Attribution 4.0 International License (CC BY-NC 4.0) which permits unrestricted use, distribution, and reproduction in any medium for non-commercial use provided the original author and source are credited.

\section{SigNifiCANCE STATEMENT}

Attention-deficit/hyperactivity

disorder (ADHD), a neurodevelopmental disorder, severely impairs academic performance and relationships. It impacts preschool-age children and can extend beyond childhood and adolescence into adulthood. When it is comorbid with major depressive disorder (MDD), it is associated with much more severe depressive symptoms, an earlier age of illness onset, more complex psychiatric comorbidities, decreased quality of life, poorer academic performance, decreased social functioning, lower work productivity, and lower employment rates than patients with MDD alone.

\section{Abbreviations \\ 5-HT \\ Serotonin \\ ADHD Attention-Deficit/Hyperactivity Disorder \\ Amy Amygdala \\ CBT Cognitive Behavioural Therapy \\ DA Dopamine}

DLPFC Dorsolateral Prefrontal Cortex

DSM-5 Diagnostic and Statistical Manual of Mental Disorders, Fifth Edition

Hip Hippocampus

MDD Major Depressive Disorder

MRI Magnetic Resonance Imaging

NA Noradrenaline

NRI Noradrenaline Reuptake Inhibitor

PFC Prefrontal Cortex

SSRI Selective Serotonin Reuptake Inhibitor

TRD Treatment-Resistant Depression

VBM Voxel-Based Morphometry 


\section{INTRODUCTION}

Attention-deficit/hyperactivity disorder (ADHD) is a neurodevelopmental disorder characterized by inattention, impulsivity, and distractibility, with or without hyperactivity [1]. There are three major subtypes described from the Diagnostic and Statistical Manual of Mental Disorders, Fifth Edition (DSM-5) of the American Psychiatric Association: predominantly inattentive, predominantly hyperactive-impulsive, and combined. In Pan African countries, the prevalence of ADHD has been estimated to differ from $5.4 \%$ to $8.7 \%$ among school children [1]. In the general population, it was recorded in $1.5 \%$ of children. In addition, children with organic brain pathology were estimated to have ADHD prevalence of $45-100 \%[2,1]$. Worldwide, the prevalence is estimated to be $5.29 \%[3,4]$.

The condition severely impairs academic performance and relationships. It impacts preschool age children and can extend beyond childhood and adolescence into adulthood. Approximately $60 \%$ to $70 \%$ of patients' symptoms persist into adulthood [5]. Strenuous research including longitudinal studies and public awareness emphasized the presence of ongoing symptoms in $65 \%$ of adult patients [6]. ADHD is more frequently observed in men than women, with a ratio of approximately 1.6:1 in adults [5]. Women are more likely than men to display primarily inattentive symptoms. Diagnoses are often reported in males, with combined subtype being the most common in all age groups [7]. The rise in adults diagnosed with ADHD is followed by the use of psychostimulants such as methylphenidate. They have unpleasant adverse effects and have a potential to cause substance use disorders [8]. Although the pathogenesis of ADHD is not fully understood, both socioeconomic [1] and biological factors [9] have been implicated in the pathogenesis of ADHD. Biological factors are likely to play a predominant role [9]. Twin studies have proven that heritability of ADHD does exist [9, 10].

Many patients with ADHD usually suffer from anhedonia and chronic unhappiness. The inability to utilize their potential creates a sense of hopelessness that many patients experience depression. Major depressive disorder (MDD) has been reported to be a major comorbidity of $\mathrm{ADHD}[11,5,12]$. MDD is a chronic disorder that often aggravates the symptoms and dysfunctions of ADHD. Patients who have both ADHD and MDD may suffer from severe dysfunctions than those with either one of these disorders. Thus, pharmacotherapy of ADHD and co-occurring MDD is a major challenge to physicians.

When ADHD is comorbid with MDD, it is associated with much more severe depressive symptoms, an earlier age of illness onset, more complex psychiatric comorbidities, decreased quality of life, greater burden of illness, greater illness complexity, poorer academic performance, decreased social functioning, lower work productivity, and lower employment rates than patients with MDD alone [1316]. Furthermore, individuals with ADHD and MDD encounter higher levels of substance abuse and psychological impairment than each disorder in isolation, and thus explaining treatment resistance in the population when treated with traditional selective serotonin reuptake inhibitors (SSRIs). One of the best predictors of comorbid ADHD with treatment-resistant depression (TRD) was the number of SSRIs the patient had failed to respond to [16]. The correlation between ADHD and depressive disorders have been established in multigeneration studies that support a genetic tie. Prevalence of ADHD in offspring of adults with recurrent depression has been found to be greater than in the general population, and that first-degree relatives of youth with ADHD display alarming rates of MDD [17].

\section{Pathophysiology}

The hypothesis of Halperin \& Schulz [18] portrayed ADHD to be mediated by subcortical neuronal dysfunction that exists early in life and remains relatively stable throughout the lifetime, potentially harmonized by prefrontal cortex (PFC) function in childhood ADHD. Proal et al. [19] supported this hypothesis by demonstrating the presence of a reduced caudate volume in patients with either persistent or childhood ADHD.

The basal ganglia are a group of subcortical nuclei that are primarily involved in motor control, motivation and reward processing [16]. They are closely interconnected with the PFC and the amygdala (Amy). They comprise the dorsal striatum (e.g. caudate nucleus, putamen), the ventral striatum (e.g. globus pallidus, ventral pallidum), the substantia nigra and the subthalamic nucleus. The caudate nucleus plays a part in governing the magnitude of a reward and helps drive appropriate behaviours necessary to obtain that reward [16]. Staggeringly, caudate and pallidum volumes negatively correlated with severity of anhedonia [20]. Anhedonia, which is a hallmark of depression, is associated with low hedonic tone which is defined as a reduced capacity to experience pleasure at any given time. Additionally, ventral striatal activity and volume negatively correlated with severity of anhedonia [16]. Dysfunction of this circuitry is observed in ADHD and MDD, proving that low hedonic tone is an important link between these psychopathologies.

Behavioural features of ADHD correlate with alterations in neural pathways that regulate reward and motivation. A meta-analysis showed significant hypoactivity in several frontal regions in patients with ADHD relative to control subjects, particularly the orbitofrontal cortices, inferior PFC, dorsolateral prefrontal cortex (DLPFC), and anterior cingulate [21]. 
Impaired neuromodulation of the DLPFC results in executive dysfunction in ADHD [22-26]. Additionally, hypoactivity was also observed in the thalamus, basal ganglia and parietal cortices [16]. Hypoactivation of areas in the frontal and parietal regions are precursors of hyperactivity in patients with ADHD [21, 28, 16]. Impulsive behaviour is a common trait of ADHD and MDD. Dysfunction of prefrontal areas, particularly the dorsolateral, ventromedial, ventrolateral, inferior frontal gyrus, rostral and dorsal anterior cingulate cortex and insula, is associated with impulsivity observed in patients with ADHD and/or MDD [29-31]. In fact, reduction in dopaminergic input to the orbital and medial PFC decreased the ability to inhibit impulsive behaviour [16].

Magnetic resonance imaging (MRI) studies have reported structural abnormalities in several regions of the brain in subjects with childhood ADHD compared to controls [7]. In a meta-analysis of structural MRI studies conducted by Valera and colleagues, they pooled data of 22 regions of interest studies comparing 565 ADHD children with 583 controls. The highest reductions in ADHD children compared to controls were found in the cerebellum, the splenium of the corpus callosum, cerebral regions and right caudate nucleus [32]. Another meta-analysis involved 7 whole-brain voxel-based morphometry (VBM) studies comparing 114 ADHD children with 143 controls. It was observed that ADHD severity positively correlated with grey matter reductions in the right putamen and globus pallidus [33].

Two studies conducted a meta-analysis which included children and adults with ADHD in order to examine age effects on grey matter volume using VBM. Both studies agreed with previous meta-analyses that volume reductions of the right globus pallidus, putamen, and the right and left caudate were significantly portrayed in childhood ADHD [34, 35]. Furthermore, Nakao and colleagues used metaregression analysis and confirmed that differences in grey matter volume in the right putamen vanished with advancing age confirming normalization in adulthood. A cross-sectional study also confirmed normalization of caudate volume throughout adolescence [36].

A longitudinal study observed that the peak of cortical thickness maturation was hindered in children with ADHD compared with healthy controls by an average of 3 years, with certain regions including frontal and temporal cortex areas being hindered in their maturation by up to 5 years [37]. A more recent longitudinal study in 234 children with ADHD and 23 matched controls exposed that maturation of cortical surface area was prolonged in the similar way as cortical thickness was [38]. Three studies of adult patients with ADHD showed significant reduction in the caudate nucleus $[39,19,40]$.
Onnink and colleagues observed significant reduction in caudate volume in $\mathrm{ADHD}$ adult patients relative to healthy controls. The right caudate volume was smaller in respect to brain sizes in male patients. The reduction in caudate volume positively correlated with severity of hyperactive and impulsive symptoms observed in ADHD. The caudate volume phenotype is a gender-specific effect only observed in males with ADHD [7]. Normalization of caudate and putamen volumes correlates with males succeeding in task performance on a response inhibition task [41, 7]. In females, enhancement of the right inferior temporal gyrus was associated with improved task performance. Hyperactivation of the precuneus, however, negatively correlated with task performance [7].

Astonishingly, the neurobiology of depression is almost identical to that of ADHD [42, 16]. MDD is a leading comorbidity of adult ADHD which has been estimated to co-occur in up to $50 \%$ of cases [14]. The DLPFC, which responds to working memory tasks, remains hypoactive in MDD [42, 43]. The medial prefrontal cortex is essential in the regulation of normal social behaviour [44]. Cortical thinning of this brain region was observed in patients with MDD [45]. Furthermore, patients with MDD exhibited significant reductions in grey matter volume in lateral, medial and orbital prefrontal cortices [96]. Additionally, MRI studies observed significant reductions in the caudate nucleus and putamen in depressive patients relative to controls $[46,47]$.

MDD is also associated with structural brain alterations in the hippocampus (Hip) and Amy, and thus both regions are important markers for depression [7]. The Hip as part of the limbic system primarily modulates emotions and mood. Several meta-analyses observed lower Hip volume in patients diagnosed with MDD compared to healthy controls [48-53, 7, 54, 55]. Two studies, however, did not find significant difference in Hip volume in ADHD patients with depressive symptoms $[56,57]$. These studies measured depressive severity using a self-report measure of current MDD symptoms, whereas Onnink et al. [7] used a clinical retrospective diagnosis of past MDD episodes. The Amy plays a major role in various types of emotional learning and regulates emotional responses to stress. Increased excitability of the Amy to stressful stimuli has been implicated in the pathogenesis of depression in adolescents [58]. This increased excitability is associated with hypoactivity of the DLPFC. Hypoactivation of the DLPFC makes it less adequate to exert its regulatory influence over the Amy [42].

Currently, limited literature studying depressive symptoms in ADHD does not provide evidence for reduced Hip volume. Amico et al. [59] studied depression severity in ADHD adults and found no significance with structural alterations of the Hip and 
Amy. However, a structural MRI study portrayed severity of depression in ADHD patients correlated with abnormal larger Amy volumes [34]. Another MRI study observed smaller left Hip volume in 'ADHD and MDD' subgroup compared to those in the ADHD group [7]. The majority of the ADHD population will experience depressive episodes in their lifetime. These episodes may delay neuroplasticity and neurogenesis of the Hip. This hypothesis is supported by a review that concluded that chronic use of antidepressants increased neurogenesis of the Hip [60].

Why are depressive symptoms more severe in $\mathrm{ADHD}$ and co-occuring MDD than in MDD alone? Gardner et al. [61] revealed that the increased severity was associated with significantly increased activity in bilateral frontal regions (Brodmann areas 8, 9, 10, 32) in the 'ADHD and MDD' subgroup compared to those in the MDD group. The authors also observed significantly decreased activity within the bilateral cerebellum in the 'ADHD and MDD' subgroup, revealing the common link of low hedonic tone in both psychopathologies.

Altered dopamine (DA) and noradrenaline (NA) signalling, which predominantly occurs in the ventral striatum, is an underlying cause of both ADHD and MDD, resulting in low hedonic tone [16]. The mesolimbic dopaminergic system plays a central role in motivated behaviours, various types of reward and cognitive processes [62]. Mesolimbic dopaminergic deficiency is implicated in the pathogenesis of ADHD as well as MDD $[62,42,16]$. The dopaminergic theory of ADHD states that ADHD is a result of DA deficits, and consequently decreased dopaminergic activity in the frontal cortex and striatum [63, 16]. The theory came from various pharmacological and imaging studies that revealed hypoactivity in those regions [64, 65]. Hypoperfusion of the forebrain DA impairs activities in various cortical regions that are manifested in ADHD and MDD. In humans, the PFC, which regulates higher cognitive functions, is modified by NA [66]. This explains how adrenergic agonists improved memory and attention in primates and rodents by activating prefrontal alpha- 2 adrenergic receptors [68, 54]. Loss of frontal cortical region degenerates the noradrenergic synapses which is a likely cause of higher order cognitive deficits [42].

Similarly, the monoamine hypothesis of depression portrays that depression is caused by decreased activity of serotonin (5-HT), NA and DA in the brain [69]. But this theory does not justify the unresponsiveness of traditional antidepressants in patients with TRD [16]. The phenomenon of TRD addresses the complexity of neurotransmitter systems regulating mood and emotional states, making mood disorders come in various forms and expressing highly variable symptoms if these circuits are altered [16].

\section{Management}

If a patient displays symptomatology of ADHD and MDD, treating the most severe or functionally impairing condition must be initiated first. If moderate-severe MDD is the most urgent clinical issue, then pharmacotherapy for MDD must be introduced immediately. The pharmacotherapy for MDD may result in attenuation of the common symptoms such as apathy and irritability [14]. Some cognitive symptoms like working memory may improve with vortioxetine $\left(\right.$ Brintellix $\left.^{\circledR}\right)$, a multimodal antidepressant [70]. Once the depression has dissolved, the patient should be re-evaluated for ADHD and if symptoms are present, treatment for ADHD should be initiated. If patient does not respond to an antidepressant, consideration should be given to reevaluate both the MDD and ADHD diagnosis and, if necessary, initiate ADHD treatment. Depression in youth with ADHD often emerges after the onset of the latter, that it is vital to diagnose and initiate treatment earlier to prevent the risk of developing MDD [11].

Psychostimulants such as methylphenidate, a noradrenaline-dopamine reuptake inhibitor, are the most frequently prescribed medications for ADHD because they have the ability to improve concentration and focus $[8,7]$. Stimulants are the first-line treatment for both childhood and persistent ADHD despite the fact that they are chemically and pharmacologically identical to illicit drugs such as amphetamine. Clinical and animal studies demonstrated potential of abuse of methylphenidate $[11,8]$. Nevertheless, there is limited evidence of its illicit effect if it is prescribed for ADHD $[11,8]$. Treatment with methylphenidate improves ADHD symptoms by normalizing dopaminergic activity of prefrontal areas $[64,71]$. Chronic stimulant treatment resulted in normal volumes of brain structures, particularly the right anterior cingulate and the cerebellar vermis [72, 73]. Two meta-regression analyses agreed that stimulant use correlated with normalization of regional grey matter volumes using VBM [56, 35]. Additionally, untreated adolescents with ADHD showed significant cortical thinning compared with patients on stimulants [74].

Stimulants improve core symptoms of ADHD in a dose-dependent fashion. They alleviate related symptoms of ADHD like on-task behaviour, academic performance, and social functioning [5]. Long-lasting, extended-release formulations are preferred because of the convenience of single-day dosage. The side effects are usually mild and transitory [5] but emotional dysregulation has been reported in ADHD patients with co-occurring psychiatric disorders, such as manic depression [75]. In case of manic depression, the use of a stimulant should be combined with mood stabilizers $[76,63]$. 
Similarly, the selective noradrenaline re-uptake inhibitor atomoxetine (Strattera ${ }^{\circledR}$ ) is another nonstimulant recommended as the first-line treatment in patients with comorbid substance abuse disorder, anxiety disorders, or severe tics [78]. However, it has demonstrated fewer efficacies in comparison to extended-release methylphenidate in ameliorating ADHD symptoms [77]. Furthermore, it may also induce suicide ideation [75] and acute liver failure [79] in ADHD children.

Traditional antidepressants such as SSRIs are unable to alleviate major depressive symptoms in a population that may have undiagnosed ADHD. Hasler et al. [80] reported anhedonia remaining in depressive patients during SSRI treatment despite other symptoms being relieved. Citalopram, an SSRI, predisposed emotional blunting by diminishing neural activation of the striatum to rewarding and negative stimuli [81]. The blunting may be manifested by inhibitory effects of 5$\mathrm{HT}$ on DA and NA through activation of $5-\mathrm{HT}_{2 \mathrm{C}}$ and 5$\mathrm{HT}_{2 \mathrm{~A}}$ receptors, respectively [82]. The effect of 5-HT on other monoamines is the cause of SSRI-induced emotional numbing [68] or indifference [83]. Some patients may develop amotivational frontal lobe syndrome which is induced by SSRIs, and is associated with apathy, demotivation and behavioural disinhibition [84].

Remarkably, noradrenaline reuptake inhibitors (NRIs), serotonin and noradrenaline reuptake inhibitors and psychostimulants are effective in ameliorating depressive symptoms in patients who poorly respond to SSRIs. The medications directly elevate extracellular DA and NA in areas such as the ventromedial prefrontal cortex and DLPFC [16]. Harmer et al. confirmed a relationship between lower noradrenergic and dopaminergic activity and depression by administering a single dose of reboxetine, an NRI, in depressive patients. Her and her colleagues reported increase in positive affective processing, and thus enhanced hedonic tone. They concluded that catecholaminergic agents have antidepressant effects by modulating emotional processing in depressive patients very early in treatment. Studies have also reported dopaminergic agents exerting antidepressant effects in humans [42, $11,16]$. For example, amineptine and nomifensine are dopamine reuptake inhibitors that possess antidepressant effects [85, 86]. Amphetamine enhances mesolimbic dopaminergic activity. When withdrawn from its users, they experience symptoms of depression [85].

A retrospective study with a large sample size concluded that ADHD medications are not contraindicated in patients with ADHD and cooccurring MDD, although cautious dosing and close monitoring is required when prescribing to patients with suicidal tendencies [11]. In fact, long-term effect of ADHD treatment was associated with decreased risk of developing depression in patients diagnosed with ADHD [11]. ADHD medications, particularly stimulants, were also associated with decreased rates of co-occurring depression. Co-occurrence between $\mathrm{ADHD}$ and MDD is prevalent yet there is limited evidence in clinical trials to address the use of ADHD medications as treatment adjuncts for MDD [11]. Psychostimulants have been used as an off-label treatment for TRD despite little evidence of therapeutic success [14]. Reasonably, a clinical trial observed that combined therapy of methylphenidate and citalopram synergistically improved mood and well-being, as well as a higher rate of remission in elderly patients [87].

Pharmacotherapy alone is not enough to ensure positive outcomes in patients with $\mathrm{ADHD}$, nor would psychosocial interventions alone be sufficient to treat ADHD [63, 5]. The NICE guidelines, ENAA and BAP guidelines proposed a multimodal treatment approach in which psychosocial interventions are complementary to pharmacological interventions to help support, improve acceptance of diagnosis, and treat co-occurring disorders such as TRD which is unresponsive to pharmacological treatments. Cognitive behavioural therapy (CBT) plus medication were superior to CBT or medication alone in managing the core symptoms of ADHD, with lesser effect on depression [88, 89]. Mindfulness awareness therapy would benefit ADHD patients with co-occurring depression because it can improve affect and mood regulation as well as sustain attention and quality of life [90]. Dialectical behaviour therapy [91], coaching [92] and exercise [93, 94] have each demonstrated benefits. Exercise has shown to enhance frontal lobe volume, executive functioning, brain-derived neurotrophic factor levels, cerebral blood flow, and dopamine and other monoamine neurotransmission in both humans and animal models [95].

\section{CONCLUSION}

ADHD is a prevalent yet undiagnosed psychopathology, with a cognitive dysfunction as a prominent trait. Research shows strong heritability and high comorbidity, particularly MDD, which can be subtyped by the presence of ADHD. High cooccurrence between ADHD and MDD is a result of their similarity with functional dysregulation of the frontal cortex and subcortical regions. Low hedonic tone is a common link between ADHD and MDD, which is a result of reduced baseline catecholaminergic activity in regions involved in reward processing and executive functions, and is a predictor of resistance to SSRI treatment. Luckily, ADHD is a treatmentresponsive disorder. Successful multimodal treatment would improve patients' quality of life and attenuate depressive symptoms. Stimulants alone are superior to antidepressants in managing ADHD with co-occurring mild-moderate MDD. If major depressive symptoms are severe, combining an ADHD medication with an 
antidepressant should be initiated synergistically to improve therapeutic outcome and prolong remission.

\section{Author Disclosure}

The author had no conflicts of interest or financial ties to disclose.

\section{REFERENCES}

1. Chinawa, J.M., Odetunde, O.I., Obu, H.A., Chinawa, A.T., Bakare, M.O., \& Ujunwa, F.A. (2014). Attention deficit hyperactivity disorder: A neglected issue in the developing world. Behavioural Neurology, 2014: 1-7.

2. Bakare, M.O. (2012). Attention deficit hyperactivity symptoms and disorder (ADHD) among African children: A review of epidemiology and co-morbidities. African Journal of Psychiatry, 15: 358-361. https://doi.org/10.4314/ajpsy.v15i5.45

3. Smith, M. (2017). Hyperactive around the world? The history of ADHD in global perspective. Social History of Medicine, 30(4): 767-787. https://doi.org/10.1093/shm/hkw127

4. Willcutt, E.G. (2012). The prevalence of DSM-IV attention-deficit/hyperactivity disorder: A metaanalytic review. Neurotherapeutics, 9: 490-499. https://doi.org/10.1007/s13311-012-0135-8

5. Schoeman, R., \& Liebenberg, R. (2017). The South African Society of Psychiatrists/Psychiatry Management Group management guidelines for adult attention-deficit/hyperactivity disorder. South African Journal of Psychiatry, 23: 1060. https://doi.org/10.4102/sajpsychiatry.v23i0.1060

6. Goldstein, S. (1997). Managing attention and learning disorders in late adolescence and adulthood. New York: Wiley.

7. Onnink, A.M.H., Zwiers, M.P., Hoogman, M., Mostert, J.C., Kan, C.C., Buitelaar, J., \& Franke, B. (2014). Brain alterations in adult ADHD: Effects of gender, treatment and comorbid depression. European Neuropsychopharmacology, 24(3): 397409. https://doi.org/10.1016/j.euroneuro.2013.11.011

8. Chu, R.K., Rosic, T., \& Samaan, Z. (2017). Adult ADHD: Questioning diagnosis and treatment in a patient with multiple psychiatric comorbidities. Case Reports in Psychiatry, 2017: 1-7. https://doi.org/10.1155/2017/1364894

9. Cortese, S., Faraone, S.V., \& Sergeant, J. (2011). Misunderstandings of the genetics and neurobiology of ADHD: Moving beyond anachronisms. American Journal of Medical Genetics, $\quad$ 156B(5): 513-516. https://doi.org/10.1002/ajmg.b.31207

10. Hudziak, J.J., \& Faraone, S.V. (2010). The new genetics in child psychiatry. Journal of the American Academy of Child and Adolescent Psychiatry, 49(8): 729-735.

11. Chang, Z., D'Onofrio, B.M., Quinn, P.D,
Lichtenstein, P., \& Larsson, H. (2017). Medication for attention-deficit/hyperactivity disorder and risk for depression: A nationwide longitudinal cohort study. Biological Psychiatry, 80(12): 916-922. https://doi.org/10.1016/j.biopsych.2016.02.018

12. Turgay, A., \& Ansari, R. (2006). Major depression with ADHD in children and adolescents. Psychiatry (Edgmont), 3(4): 20-32.

13. Bond, D.J., Hadjipavlou, G., Lam, R.W., McIntyre, R.S., Beaulieu, S., Schaffer, A., \& Weiss, M. (2012). The Canadian Network for Mood and Anxiety Treatments (CANMAT) task force recommendations for the management of patients with mood disorders and comorbid attentiondeficit/hyperactivity disorder. Annals of Clinical Psychiatry, 24(1): 23-37.

14. McIntosh, D., Kutcher, S., Binder, C., Levitt, A., Fallu, A., \& Rosenbluth, M. (2009). Adult ADHD and comorbid depression: A consensus-derived diagnostic algorithm for ADHD. Neuropsychiatric Disease and Treatment, 5: 137-150.

15. McIntyre, R.S., Kennedy, S.H., Soczynska, J.K., Nguyen, H.T.T., Bilkey, T.S., Woldeyohannes, H.O., .. Muzina, D.J. (2010). Attentiondeficit/hyperactivity disorder in adults with bipolar disorder or major depressive disorder: Results from the international mood disorders collaborative project. Primary Care Companion to The Journal of Clinical Psychiatry, 12(3). https://doi.org/10.4088/PCC.09m00861 gry

16. Sternat, T., \& Katzman, M.A. (2016). Neurobiology of hedonic tone: The relationship between treatment-resistant depression, attentiondeficit hyperactivity disorder, and substance abuse. Neuropsychiatric Disease and Treatment, 12 . 2149-2164. https://doi.org/10.2147/NDT.S111818

17. Biederman, J., Mick, E., \& Faraone, S.V. (1998). Depression in attention deficit hyperactivity disorder (ADHD) children: "True", depression or demoralization? Journal of Affective Disorders, 47: 113-122.

18. Halperin, J.M., \& Schulz, K.P. (2006). Revisiting the role of the prefrontal cortex in the pathophysiology of attention-deficit/hyperactivity disorder. Psychological Bulletin, 132(4): 560-581. https://doi.org/10.1037/0033-2909.132.4.560

19. Proal, E., Ph.D., Reiss, P.T., Ph.D., Klein, R. G., Ph.D., ... Castellanos, F.X. (2013). Brain gray matter deficits at 33-year follow-up in adults with attention-deficit/hyperactivity disorder established in childhood. Archives of General Psychiatry, 68(11): 1122-1134. https://doi.org/10.1001/archgenpsychiatry.2011.11 7

20. Wang, Y., Deng Y., Fung G., Liu, W.H., Wei, X.H., Jiang, X.Q., ... Chan, R.C. (2014). Distinct structural neural patterns of trait physical and social anhedonia: Evidence from cortical thickness, subcortical volumes and inter-regional correlations. Psychiatry Research, 224(3): 184-191. 
21. Dickstein, S.G., Bannon, K., Castellanos, F.X., \& Milham, M.P. (2006). The neural correlates of attention deficit hyperactivity disorder: An ALE meta-analysis. Journal of Child Psychology \& Psychiatry, $\quad$ 47(10): 1051-1062. https://doi.org/10.1111/j.1469-7610.2006.01671.x

22. Cunha, P.J., Gonçalves, P.D., Ometto, M., Santos, B., Nicastri, S., Busatto, G.F., \& de Andrade, A.G. (2013). Executive cognitive dysfunction and ADHD in cocaine dependence: Searching for a common cognitive endophenotype for addictive disorders. Frontiers in Psychiatry, 4(10): 1-9. https://doi.org/10.3389/fpsyt.2013.00126

23. Fuermaier, A. B. M., Tucha, L., Koerts, J., Aschenbrenner, S., Westermann, C., Weisbrod, M., ... Tucha, O. (2013). Complex prospective memory in adults with attention deficit hyperactivity disorder. PLoS One, 8(3): 1-9. https://doi.org/10.1371/journal.pone.0058338

24. Madhoo, M., Keefe, R.S.E., Roth, R.M., Sambunaris, A., Wu, J., Trivedi, M.H., ... Lasser, R. (2014). Lisdexamfetamine dimesylate augmentation in adults with persistent executive dysfunction after partial or full remission of major depressive disorder. Neuropsychopharmacology, 39(6): 1388-1398. https://doi.org/10.1038/npp.2013.334

25. Missonnier, P., Hasler, R., Perroud, N., Herrmann, F.R., Millet, P., Richiardi, J., Malafosse A., Giannakopoulos, P., \& Baud, P. (2013). EEG anomalies in adult ADHD subjects performing a working memory task. Neuroscience, 241: 135146. https://doi.org/10.1016/j.neuroscience.2013.03 .011

26. Qian, Y., Shuai, L., Chan, R.C., Qian, Q.J., \& Wang, Y. (2013). The developmental trajectories of executive function of children and adolescents with attention deficit hyperactivity disorder. Research in Developmental Disabilities, 34(5): 1434-1445. https://doi.org/10.1016/j.ridd.2013.01.033

27. Pizzagalli, D.A., Jahn, A.L., \& Shea, J.P.O. (2008). Toward an objective characterization of an anhedonic phenotype: A signal-detection approach. Biological Psychiatry, 57(4): 319-327.

28. Hesslinger, B., Tebartz van Elst, L., Nyberg, E., Dykierek, P., Richter, H., Berner, M., \& Ebert, D. (2002b). Psychotherapy of attention deficit hyperactivity disorder in adults: A pilot study using a structured skills training programme. European Archives of Psychiatry and Clinical Neuroscience, 252(4): 177-184. https://doi.org/10.1007/s00406002-0379-0

29. Alvarez, J.A., \& Emory, E. (2006). Executive function and the frontal lobes: A meta-analytic review. Neuropsychology Review, 16(1): 17-42.

30. Aron, A.R., Robbins, T.W., \& Poldrack, R.A. (2014). Inhibition and the right inferior frontal cortex: One decade on. Trends in Cognitive Sciences, $18(4)$ : 177-185. https://doi.org/10.1016/j.tics.2013.12.003
31. Laird, A.R., McMillan, K.M., Lancaster, J.L., Kochunov, P., Turkeltaub, P.E., Pardo, J.V., \& Fox, P.T. A comparison of label-based review and ALE meta-analysis in the Stroop task. Human Brain Mapping, 25(1): 6-21. https://doi.org/10.1002/hbm.20129

32. Valera, E.M., Faraone, S.V, Murray, K.E., \& Seidman, L.J. (2007). Meta-analysis of structural imaging findings in attention-deficit/hyperactivity disorder. Biological Psyhciatry, 61: 1361-1369. https://doi.org/10.1016/j.biopsych.2006.06.011

33. Ellison-wright, I., Ellison-wright, Z., \& Bullmore, E. (2008). Structural brain change in attention deficit hyperactivity disorder identified by metaanalysis. BMC Psychiatry, 8: 1-8. https://doi.org/10.1186/1471-244X-8-51

34. Frodl, T., Stauber, J., Schaaff, N., Koutsouleris, N., \& Scheuerecker, J. (2010). Amygdala reduction in patients with ADHD compared with major depression and healthy volunteers. Acta Psychiatrica Scandinavica, 121(2): 111-118. https://doi.org/10.1111/j.1600-0447.2009.01489.x

35. Nakao, T., Radua, J., Rubia, K., \& Mataix-Cols, D. (2011). Gray matter volume abnormalities in ADHD: Voxel-based meta-analysis exploring the effects of age and stimulant medication. American Journal of Psychiatry, 168: 1154-1163.

36. Castellanos, F.X., Lee, P.P., Sharp, W., Jeffries, N.O., Greenstein, D.K., Clasen, L.S., ... Rapport, J.L. (2002). Developmental trajectories of brain volume abnormalities in children and adolescents with attention-deficit/hyperactivity disorder. Journal of American Medical Association, 288: 1740-1748.

37. Shaw, P., Eckstrand, K., Sharp, W., Blumenthal, J., Lerch, J. P., Greenstein, D., ... Evans, A. (2007). Attention-deficit/hyperactivity disorder is characterized by a delay in cortical maturation. Proceedings of the National Academy of Sciences of the USA, 104(49): 1-6.

38. Shaw, P., Malek, M., Watson, B., Sharp, W., Evans, A., \& Greenstein, D. (2012). Development of cortical surface area and gyrification in attention-deficit/hyperactivity disorder. Biological Psychiatry, 72(3): 191-197. https://doi.org/10.1016/j.biopsych.2012.01.031

39. Almeida Montes, L.G., Ricardo-Garcell, J., Barajas De La Torre, L.B., Prado Alcantara, H., Martinez Garcia, R.B., Fernandez-Bouzas, A., \& Avila Acosta, D. (2010). Clinical correlations of grey matter reductions in the caudate nucleus of adults with attention deficit hyperactivity disorder. Journal of Psychiatry \& Neuroscience, 35: 238 246.

40. Seidman, L.J., Biederman, J., Liang, L., Valera, E.M., Monuteaux, M.C., Brown, A., ... Makris, N. (2011). Gray matter alterations in adults with attention-deficit/hyperactivity disorder identified by voxel based morphometry. Biological Psychiatry, 69(9): 857-866. 
https://doi.org/10.1016/j.biopsych.2010.09.053

41. Casey, B.J., Ph.D., Castellanos, F.X., Giedd, J.A.Y.N., Marsh, W.L., Hamburger, S.D., ... Rapoport, J.L. (1997). Implication of right frontostriatal circuitry in response inhibition and attention-deficit hyperactivity disorder. Journal of the American Academy of Child \& Adolescent Psychiatry, 36(3): 374-383. https://doi.org/10.1097/00004583-19970300000016

42. Basak, A.K., \& Chatterjee, T. (2016). Structural and neurochemical alterations in brain regions of depression and suicide patients. Clinical Depression, 2(3). https://doi.org/10.4172/25720791.1000117

43. Koenigs, M., \& Grafman, J. (2009). The functional neuroanatomy of depression: Distinct roles for ventromedial and dorsolateral prefrontal cortex. Behavioural Brain Research, 201(2): 239-243. https://doi.org/10.1016/j.bbr.2009.03.004

44. Grossmann, T. (2013). The role of medial prefrontal cortex in early social cognition. Frontiers in Human Neuroscience, 7: 340.

45. Canu, E., Kostić, M., Agosta, F., Munjiza, A., Ferraro, P.M., Pesic, D., Copetti, M., Peljto, A., Lecic Tosevski, D., \& Filippi, M. (2015). Brain structural abnormalities in patients with major depression with or without generalized anxiety disorder comorbidity. Journal of Neurology, 262(5):

1255-1265. https://doi.org/10.1007/s00415-015-7701-z

46. Husain, M.M., McDonald, W.M., Doraiswamy, P.M., Figiel, G.S., Na, C., Escalona, P.R., Boyko, O.B., Nemeroff, C.B., \& Krishnan, K.R. (1991). A magnetic resonance imaging study of putamen nuclei in major depression. Psychiatry Research, 40(2): 95-99.

47. Parashos, I.A., Tupler, L.A., Blitchington, T., \& Krishnan, K.R. (1998). Magnetic-resonance morphometry in patients with major depression. Psychiatry Research, 84(1): 7-15.

48. Arnone, D., Mcintosh, A. M., Ebmeier, K. P., Munafò, M. R., \& Anderson, I. M. (2012). Magnetic resonance imaging studies in unipolar depression: Systematic review and meta-regression analyses. European Neuropsychopharmacology, 22(1): $1-16$. https://doi.org/10.1016/j.euroneuro.2011.05.003

49. Cole, J., Costafreda, S.G., Mcguf, P., \& Fu, C.H.Y. (2011). Hippocampal atrophy in first episode depression: A meta-analysis of magnetic resonance imaging studies. Journal of Affective Disorders, 134(2011): 483-487. https://doi.org/10.1016/j.jad.2011.05.057

50. Du, M., Wu, Q., Yue, Q., Li, J., Liao, Y., Kuang, W., ... Gong, Q. (2012). Voxelwise meta-analysis of gray matter reduction in major depressive disorder. Progress in Neuropsychopharmacology \& Biological Psychiatry, 36(1): 11-16. https://doi.org/10.1016/j.pnpbp.2011.09.014
51. Frodl, T., Schaub, A., Banac, S., Charypar, M., Jäger, M., Kümmler, P., ... Meisenzahl, E.M. (2006). Reduced hippocampal volume correlates with executive dysfunctioning in major depression. Journal of Psychiatry \& Neuroscience, 31(5): 316323.

52. Kempton, M.J., Salvador, Z., Munafò, M.R., Geddes, J.R., Simmons, A., Frangou, S., \& Williams S.C. (2011). Structural neuroimaging studies in major depressive disorder. Meta-analysis and comparison with bipolar disorder. Archives of General Psychiatry, 68(7): 675-690. https://doi.org/10.1001/archgenpsychiatry.2011.60

53. Koolschijn, P.C., van Haren, N.E., LensveltMulders, G.J., Hulshoff Pol, H.E., \& Kahn, R.S. (2009). Brain volume abnormalities in major depressive disorder: A meta-analysis of magnetic resonance imaging studies. Human Brain Mapping, $30(11)$ :

3719-3735. https://doi.org/10.1002/hbm.20801

54. Sheline, Y.I., Vanniertt, M.W., Wang, P.O.W., Gadots, M.H., \& Csernansky, J.G. (1996). Hippocampal atrophy in recurrent major depression. Proceedings of the National Academy of Sciences of the USA, 93(9): 3908-3913.

55. Videbech, P., \& Ravnkilde, B., Ph.D. (2004). Reviews and overviews hippocampal volume and depression: A meta-analysis of MRI studies. American Journal of Psychiatry, 161: 1957-1966.

56. Frodl, T., \& Skokauskas, N. (2012). Meta-analysis of structural MRI studies in children and adults with attention deficit hyperactivity disorder indicates treatment effects. Acta Psychiatrica Scandinavica, $\quad$ 125(2): 114-126. https://doi.org/10.1111/j.1600-0447.2011.01786.x

57. Perlov, E., Philipsen, A., van Elst, L.T., Ebert, D., Henning, J., Maier, S., ... Hesslinger, B. (2008). Hippocampus and amygdala morphology in adults with attention-deficit hyperactivity disorder. Journal of Psychiatry \& Neuroscience, 33(6): 509515.

58. Swartz, J.R., Ph.D., Williamson, D.E., Ph.D., \& Hariri, A.R., Ph.D. (2015). Developmental change in amygdala reactivity during adolescence: Effects of family history for depression and stressful life events. American Jourrnal of Psychiatry, 172(3): 276-283. https://doi.org/10.1176/appi.ajp.2014.14020195

59. Amico, F., Stauber, J., Koutsouleris, N., \& Frodl, T. (2011). Anterior cingulate cortex gray matter abnormalities in adults with attention deficit hyperactivity disorder: A voxel-based morphometry study. Psychiatry Research: Neuroimaging, $\quad$ 191(1): 31-35. https://doi.org/10.1016/j.pscychresns.2010.08.011

60. Kheirbek, M.A., \& Hen, R. (2011). Dorsal vs ventral hippocampal neurogenesis: Implications for cognition and mood. Neuropsychopharmacology, 36(1): 373-374.

61. Gardner, A., Salmaso, D., Varrone, A., Sanchez- 
Crespo, A., Bejerot, S., Jacobsson, H., Larsson, S.A., \& Pagani, M. (2009). Differences at brain SPECT between depressed females with and without adult ADHD and healthy controls: Etiological considerations. Behavioral and brain functions, 5: 37. https://doi.org/10.1186/17449081-5-37

62. Alcaro, A., Huber, R., \& Panksepp, J. (2007). Behavioral functions of the mesolimbic dopaminergic system: An affective neuroethological perspective. Brain Research Reviews, 56(2): 283-321.

63. Geffen, J., \& Forster, K. (2018). Treatment of adult ADHD: A clinical perspective. Therapeutic Advances in Psychopharmacology, 8(1): 25-32. https://doi.org/10.1177/https

64. Kim, B.N., Lee, J.S., Cho, S.C., \& Lee, D.S. (2001). Methylphenidate increased regional cerebral blood flow in subjects with attention deficit/hyperactivity disorder. Yonsei Medical Journal, 42(1): 19-29. https://doi.org/10.3349/ymj.2001.42.1.19

65. Kim, B.N., Lee, J.S., Shin, M.S., Cho, S.C., \& Lee, D.S. (2002). Regional cerebral perfusion abnormalities in attention deficit/hyperactivity disorder. Statistical parametric mapping analysis. European Archives of Psychiatry and Clinical Neuroscience, 252(5): 219-225.

66. Ordway, G.A., Klimek, V. \& Mann, J.J. (2002). Neurocircuitry of mood disorders. Neuropsychopharmacology: The Fifth Generation of Progress, 1051-1064.

67. Arnsten, A.F.T., Cai, J.X., \& Goldman, P.S. (1988). The alpha-2 adrenergic agonist guanfacine improves memory in aged monkeys without sedative or hypotensive side effects: Evidence for alpha-2 receptor subtypes. The Journal of Neuroscience, 8(11): 4287-4298.

68. Arnsten, A.F., \& Rubia, K. (2012). Neurobiological circuits regulating attention, cognitive control, motivation, and emotion: Disruptions in neurodevelopmental psychiatric disorders. Journal of the American Academy of Child and Adolescent Psychiatry, 51(4): 356-367. https://doi.org/10.1016/j.jaac.2012.01.008

69. Krishnan, V., \& Nestler, E.J. (2008). The molecular neurobiology of depression. Nature, 455(7215): 894-902. https://doi.org/10.1038/nature07455

70. Baune, B.T., Brignone, M., \& Larsen, K.G. (2018). A network meta-analysis comparing effects of various antidepressant classes on the digit symbol substitution test (DSST) as a measure of cognitive dysfunction in patients with major depressive disorder. International Journal of Neuropsychopharmacology, 21(2): 97-107. https://doi.org/10.1093/ijnp/pyx070

71. Lee, J.S., Kim, B.N., Kang, E., Lee, D.S., Kim, Y.K., Chung, J.K., Lee, M.C., \& Cho, S.C. (2005). Regional cerebral blood flow in children with attention deficit hyperactivity disorder: Comparison before and after methylphenidate treatment. Human Brain Mapping, 24(3): 157-164. https://doi.org/10.1002/hbm.20067

72. Bledsoe, J., Semrud-Clikeman, M., \& Pliszka, S.R. (2009). An MRI study of the cerebellar vermis in chronically-treated and treatment-naïve children with ADHD-combined type. Biological Psychiatry, 65(7): 620-624. https://doi.org/10.1016/j.biopsych.2008.11.030

73. Pliszka, S.R., Glahn, D.C., Semrud-Clikeman, M., Franklin, C., Xiong, J. \& Liotti, M. Neuroimaging of inhibitory control areas in children with attention deficit hyperactivity disorder who were treatment naive or in long-term treatment. American Journal of Psychiatry, 163: 1052-1060.

74. Shaw, P., Sharp, W., Morrison, M., Eckstrand, K., Greenstein, D., Clasen, L., ... Rapoport, J.L. (2009). Psychostimulant treatment and the developing cortex in attention-deficit/hyperactivity disorder. American Journal of Psychiatry, 166(1): 58-63.

https://doi.org/10.1176/appi.ajp.2008.08050781.Ps ychostimulant

75. Clemow, D.B., Bushe, C., Mancini, M., Ossipov, M.H., \& Upadhyaya, H. (2017). A review of the efficacy of atomoxetine in the treatment of attention-deficit hyperactivity disorder in children and adult patients with common comorbidities. Neuropsychiatric Disease and Treatment, 13: 357361.

76. Asherson, P., Young, A.H., Eich-Höchli, D., Moran, P., Porsdal, V., \& Deberdt, W. (2014). Differential diagnosis, comorbidity, and treatment of attention-deficit/hyperactivity disorder in relation to bipolar disorder or borderline personality disorder in adults. Current Medical Research and Opinion, 30(8): 1657-1672. https://doi.org/10.1185/03007995.2014.9115800

77. Hanwella, R., Senanayake, M., \& de Silva, V. (2011). Comparative efficacy and acceptability of methylphenidate and atomoxetine in treatment of attention deficit hyperactivity disorder in children and adolescents: A meta-analysis. BMC Psychiatry, 11(1): 176. https://doi.org/10.1186/1471-244X-11176

78. Bolea-Alamañac, B., Nutt, D. J., Adamou, M., Bazire, S., Coghill, D., Heal, D., ... Sayal, K. (2015). Evidence-based guidelines for the pharmacological management of attention deficit hyperactivity disorder: Update on recommendations from the British Association for Psychopharmacology. Journal of Psychopharmacology, 28(3), 179-203. https://doi.org/10.1177/0269881113519509

79. Erdogan, A., Ozcay, F., Piskin, E., Karaman, M.G., Bilezikci, B., Calik, M., Tekin, I., \& Haberal, M. (2011). Idiosyncratic liver failure probably associated with atomoxetine: A case report. Journal of Child and Adolescent 


\section{Psychopharmacology, 21(3): 295-297.} https://doi.org/10.1089/cap.2010.0101

80. Hasler, G., Drevets, W.C., Manji, H.K., \& Charney, D.S. (2004). Discovering endophenotypes for major depression. Neuropsychopharmacology, 29(10): 1765-1781. https://doi.org/10.1038/sj.npp.1300506

81. McCabe, C., Mishor, Z., Cowen, P.J., \& Harmer, C.J. (2010). Diminished neural processing of aversive and rewarding stimuli during selective serotonin reuptake inhibitor treatment. Biological Psychiatry, 67(5): 439-445.

82. Trivedi, M.H., Hollander, E., Nutt, D., \& Blier, P. (2008). Clinical evidence and potential neurobiological underpinnings of unresolved symptoms of depression. Journal of Clinical Psychiatry, 69(2): 246-258

83. Sansone, R.A., \& Sansone, L.A. (2010). SSRIinduced indifference. Psychiatry (Edgmont), 7(10): 14-18.

84. Garland, E.J., \& Baerg, E.A. (2001). Amotivational syndrome associated with selective serotonin reuptake inhibitors in children and adolescents. Journal of Child and Adolescent Psychopharmacology, 11(2): 181-186. https://doi.org/10.1089/104454601750284090

85. Kinney, J.L. (1985). Nomifensine maleate: A new second-generation antidepressant. The Journal of Clinical Pharmacology, 4(6): 625-636.

86. Roy, A., Agren, H., Pickar, D., Linnoila, M., Doran, A.R., Cutler, N.R., \& Paul, S.M. (1986). Reduced CSF concentrations of homovanillic acid and homovanillic acid to 5-hydroxyindoleacetic acid ratios in depressed patients: Relationship to suicidal behavior and dexamethasone nonsuppression. American Journal of Psychiatry, 143: 1539-1545.

87. Lavretsky, H., Reinlieb, M., St. Cyr., N., Siddarth, P., Ercoli, L.M., \& Senturk, D. (2015). Combined citalopram and methylphenidate improved treatment response compared to either drug alone in geriatric depression: A randomized double-blind, placebo-controlled trial. American Journal of Psychiatry, 172(6): 561-569. https://doi.org/10.1176/appi.ajp.2014.14070889

88. Safren, S.A., Otto, M.W., Sprich, S., Winett, C.L., Wilens, T.E., \& Biederman, J. (2005). Cognitivebehavioral therapy for ADHD in medication- treated adults with continued symptoms. Behavior Research and Therapy, 43(7): 831-842. https://doi.org/10.1016/j.brat.2004.07.001

89. Young, S., Khondoker, M., Emilsson, B., \& Sigurdsson, J.F. (2015). Cognitive-behavioural therapy in medication-treated adults with attentiondeficit/hyperactivity disorder and co-morbid psychopathology: A randomized controlled trial using multi-level analysis. Psychological Medicine, 45: 2793-2804. https://doi.org/10.1017/S0033291715000756

90. Bueno, V.F., Kozasa, E.H., Aparecida, M., Alves, T.M., Louzã, M.R., \& Pompéia, S. (2015). Mindfulness meditation improves mood, quality of life, and attention in adults with attention deficit hyperactivity disorder. BioMed Research International, 2015: 1-14. http://dx.doi.org/10.1155/2015/962857

91. Hesslinger, B., Elst, L.T. Van, Thiel, T., Haegele, K., Hennig, J., \& Ebert, D. (2002a). Frontoorbital volume reductions in adult patients with attention deficit hyperactivity disorder. Neuroscience Letters, 328: 319-321.

92. Prevatt, F., \& Yelland, S. (2013). An empirical evaluation of ADHD coaching in college students. Journal of Attention Disorders, 19(8): 666-677. https://doi.org/10.1177/1087054713480036

93. Den Heijer, A.E., Groen, Y., Tucha, L., Fuermaier, A.B.M., Koerts, J., Lange, K.W., ... Tucha, O. (2017). Sweat it out? The effects of physical exercise on cognition and behavior in children and adults with ADHD: A systematic literature review. Journal of Neural Transmission, 124(s1): 3-26. https://doi.org/10.1007/s00702-016-1593-7

94. Vysniauske, R., Verburgh, L., Oosterlaan, J., \& Molendijk, M.L. (2016). The effects of physical exercise on functional outcomes in the treatment of ADHD. Journal of Attention Disorders. https://doi.org/10.1177/1087054715627489

95. Randolph, J. (2015). Lifestyle factors and ADHD: The positive role of physical activity. National Academy of Neuropsychology, 30(1): 14-15.

96. Grieve, S.M., Korgaonkar, M.S., Koslow, S.H., Gordon, E., \& Williams, L.M. (2013). Widespread reductions in gray matter volume in depression. NeuroImage: Clinical, 3: 332-339. https://doi.org/10.1016/j.nicl.2013.08.016. 